\title{
A atuação do profissional da saúde no SUS: a responsabilidade por erro médico no serviço público em perspectiva jurídica
}

\author{
Juridical perspective of malpractice liability in the public service
}

\section{João Paulo K. Forster}

Advogado, mestre e doutorando em Direito Processual Civil. Professor no Centro Universitário Ritter dos Reis. Porto Alegre, Brasil.

Resumo: Este trabalho enfrenta a questão da responsabilidade dos profissionais da saúde no ambiente do Sistema Único de Saúde, com destaque para as mais recentes decisões judiciais a respeito do tema. No âmbito do SUS, existe uma ampla gama de profissionais executando seus serviços, a partir de organização estatal prédeterminada. Para cada uma dessas áreas, há diversas construções doutrinárias e jurisprudenciais sobre diferentes níveis de responsabilidade, muitas vezes sem considerar as particularidades do próprio Sistema Único. A questão que se impõe é se é possível analisar tais condutas a partir dos mesmos paradigmas presentes na esfera privada, na qual regularmente se aplica o Código de Defesa do Consumidor, conforme art. 14, $\S 4^{\circ}$, da Lei 8.078/90. Portanto, em primeiro lugar, examina-se o enquadramento jurídico da vinculação entre o profissional e o Estado, bem como a administração descentralização do SUS. Em seguida, passa-se ao estudo da legislação aplicável a tais situações, com o devido cuidado de apontar as idiossincrasias do serviço público, especialmente no Brasil. Finalmente, perquire-se o que os tribunais pátrios decidem sobre o tema, e se há maciça (ir)responsabilização dos profissionais da saúde, em particular os médicos, a fim de restringir e aprofundar o presente estudo, com o devido apontamento da (im)possibilidade de diferenciação na prestação de serviços na seara privada ou pública nos deveres a serem atendidos.

Palavras-Chave: Erro médico; SUS; responsabilidade civil

Keywords: Malpractice; SUS; liability

\section{Introdução}

O tema da responsabilidade de qualquer profissional na área da saúde é tema extremamente delicado, mormente quando se começam a traçar distinções entre a atuação pública ou privada de tais indivíduos. O fato é que, no Sistema Único de Saúde - SUS, existe a execução de ampla gama de serviços das mais diversas áreas da saúde, sem que haja uma sinalização evidente da responsabilização de tais 
agentes ou deste ou aquele ente político na medida das limitações do próprio sistema.

Assim, faz-se relevante a distinção a ser operada entre os profissionais da saúde no âmbito público ou privado, em particular na perspectiva da jurisprudência a partir da leitura das Leis $8.078 / 90$ e $8.080 / 90$ e suas consequências para os profissionais da saúde.

\section{Descentralização e responsabilidade no sistema único de saúde}

A lei 8.080/90 bem estabeleceu as bases de que o Sistema Único de Saúde é descentralizado, no que já dispunha o art. 198, I, da Constituição Federal, a partir da leitura dos artigos 16-18 da lei, nos quais são estabelecidas as competências federais, estaduais e municipais sobre sua administração. O referido dispositivo legal vem sendo empregado pelas Cortes nacionais a fim de ressaltar tal característica, a fim de apurar corretamente as responsabilidades em caso de necessidade de indenização. ${ }^{1}$ Ressalve-se que, a partir do caso concreto, é que podem ser verificados regimes de responsabilidade diferentes, sendo indicada precaução na definição apriorística de quem efetivamente é o responsável pela reparação.

Nessa quadra, há nítida diferenciação quando de se trata de responsabilidade ${ }^{2}$ pela ocorrência do chamado erro médico ${ }^{3}$ e pelo fornecimento de medicamentos. No

1 ADMINISTRATIVO. PROCESSUAL CIVIL. AGRAVO REGIMENTAL NOS EMBARGOS DE DECLARAÇÃO NO RECURSO ESPECIAL. RESPONSABILIDADE CIVIL POR ERRO MÉDICO. HOSPITAL PRIVADO. ATENDIMENTO CUSTEADO PELO SUS. ILEGITIMIDADE PASSIVA DA UNIÃO. PRECEDENTES. AGRAVO NÃO PROVIDO. 1. Segundo entendimento do Superior Tribunal de Justiça, "A União não possui legitimidade passiva nas ações de indenização por falha em atendimento médico ocorrida em hospital privado credenciado no SUS, tendo em vista que, de acordo com a descentralização das atribuições determinada pela Lei 8.080/1990, a responsabilidade pela fiscalização é da direção municipal do aludido sistema" (Brasil. TJPR, 2010). 2. Não há falar em legitimidade passiva da União, responsável, na condição de gestora nacional do SUS: (a) pela elaboração de normas para regular as relações entre o sistema e os serviços privados contratados de assistência à saúde; (b) pela promoção da descentralização para os Estados e Municípios dos serviços e ações de saúde, respectivamente, de abrangência estadual e municipal; e (c) pelo acompanhamento, controle e avaliação das ações e dos serviços de saúde, respeitadas as competências estaduais e municipais (Lei 8.080/90, art. 16, XIV, XV e XVII). 3. Agravo regimental não provido. (Brasil. STJ, 2012).

2 "A responsabilidade representa para o fenômeno do poder o seu enfrentamento necessário e o seu correlato ético. Por meio da responsabilidade, o uso do poder deve ser conduzido em direção a uma humana, a serviço do ser humano." (Kress, 2008, p. 21).

${ }^{3} \mathrm{O}$ termo admite amplas possibilidades, verificando-se "na fase diagnóstica, na fase de informação ao paciente e na fase terapêutica. Podem ocorrer ainda nos prognósticos", destacando-se, sempre que possível, que "a medicina, como o direito, não é uma ciência exata." (Forster, 2003, p. 35/36). Por conta dessa consideração, mostra-se adequado o entendimento de que "não existe (...) outra atividade mais vulnerável que a medicina, chegando a ser uma das mais difíceis de se exercer sob o ponto de 
primeiro caso, há de se perquirir aqueles que estão diretamente envolvidos na ocorrência do evento danoso, enquanto que no último, diante da noção de máximo assistencialismo, todos são solidariamente responsáveis. ${ }^{4}$ Nos casos de responsabilidade civil, o entendimento acerca de quem deva reparar é diferenciado. Todavia, ainda que o Sistema Único de Saúde não se preste a solidariamente colocar todos os entes políticos como responsáveis em caso de erro médico, também não pode servir de escudo para a impunidade e total irresponsabilidade dos agentes do sistema. A tal respeito, bem decidiu o Superior Tribunal de Justiça que

responde o hospital pelo ato culposo praticado por profissional de sua equipe médica, mesmo que sem vínculo empregatício com a instituição. A circunstância de os serviços médicos terem sido prestados gratuitamente, ou remunerados pelo SUS, não isenta o profissional e a instituição da responsabilidade civil por erro médico (Brasil. STJ, 2013 a).

A dicção do art. 37, §6º da Carta Constitucional de 1988 prevê a responsabilidade das pessoas jurídicas de direito público e das privadas prestadores de serviços públicos pelos danos causados pelos seus agentes. Não poderia lei ordinária posterior, muito menos singelo entendimento jurisprudencial, reduzir a eficácia e o alcance de tal disposição constitucional, sendo indispensáveis apenas os requisitos elementares para caracterização da responsabilização: personalidade jurídica (o que reacende o debate de quem deva responder no âmbito do SUS, aí remetendo para a Lei 8.080/90 para a determinação de qual órgão político seja

vista legal. (...). O erro presumido é uma das acusações mais frequentes. Os doentes também culpam o não-esclarecimento prévio de uma intervenção mesmo quando a operação se apresenta dentro das exigências da técnica e da lei." (França, 2007, p. 219).

4 "Consoante o entendimento do egrégio Superior Tribunal de Justiça, o município, na condição de gestor local do sistema de saúde, possui legitimidade para responder ações em que o atendimento pelo hospital é realizado pelo SUS, consoante o disposto no artigo 18 da Lei no $8.080 / 1990$, ainda que se trate de hospital da rede particular. Solidariedade dos entes federativos - Afora os casos de distribuição de medicamentos, donde a solidariedade exsurge do próprio texto magno e já conta com orientação jurisprudencial consolidada no sentido de compreender a solidariedade entre os entes federativos de atuação do sistema de saúde união, estado e município, o que se justifica até pelo máximo princípio do assistencialismo, situação diversa se passa nos casos de responsabilidade médica ou institucional do nosocômio, ocasionada por qualquer das modalidades da culpa. Nesses casos não há como enxergar solidariedade passiva da união ou do estado, nem mesmo do município, ainda que o gestor local do sistema de saúde, mormente se descentralizado. A solidariedade dos entes federativos: União, estado e município é pelo funcionamento do SUS, pela disposição à coletividade de um sistema público de saúde gratuito e universal." (Brasil. TJRS, 2013 a). Complementa-se: "Por mais que os poderes públicos, como destinatários precípuos de um direito à saúde, venham a opor - além da clássica alegação de que o direito à saúde (a exemplo dos direitos sociais prestacionais em geral) foi positivado como norma de eficácia limitada - os habituais argumentos da ausência de recursos e da incompetência dos órgãos judiciários para decidirem sobre alocação e destinação de recursos públicos, não nos parece que esta solução possa prevalecer, ainda mais nas hipóteses em que está em jogo a preservação do bem maior da vida humana." (Sarlet et al., 2012, p. 578). 
imediatamente responsável) e os demais requisitos tradicionais: culpa, dano e nexo causal.

No que toca ao elemento culpa, cabe apenas considerar que segue em grande medida aberto o debate da responsabilização objetiva (tradicional quando se trata de responsabilidade estatal ou de empresa privada prestadora de serviço público) (Gonçalves, 2003, p. 176/177), por conta da compreensão jurisprudencial acerca da necessidade de perquirir, nos casos de erro médico, a responsabilidade do profissional mesmo quando este não seja réu na ação indenizatória, cuja culpa será analisada sempre no viés subjetivo, a partir do que dispõe o art. 14 , $§ 4^{\circ}$, do Código de Defesa do Consumidor. ${ }^{5}$

A análise da responsabilidade dos agentes que atuam na área da saúde, seja em âmbito público ou privado, revela-se tema fundamental para que se possa determinar quem é efetivamente responsável pela reparação de eventuais danos causados.

\section{Responsabilidade de profissionais da saúde na perspectiva privada}

Os profissionais a saúde atuam em área de notório risco, cuja atividade achase intensamente vigiada pelo paciente que, ainda não seja leigo, não se encontra na melhor posição para uma avaliação objetiva da situação, ou por seus familiares, igualmente envolvidos no tema, prejudicando sua análise. Assim, o tema do erro profissional é sempre bastante delicado, cabendo avaliar exatamente do que se trata a noção de $\operatorname{errar}^{6}$ do profissional da saúde.

O espectro dessa falta é bastante amplo, já que os profissionais da saúde (notadamente os médicos) atuam desde o diagnóstico, até o tratamento e

\footnotetext{
5 "No julgamento do REsp 258.389/SP, da relatoria do eminente Ministro Fernando Gonçalves (DJ de 16.6.2005), este Pretório já decidiu que "a responsabilidade dos hospitais, no que tange à atuação técnico-profissional dos médicos que neles atuam ou a eles sejam ligados por convênio, é subjetiva, ou seja, dependente da comprovação de culpa dos prepostos, presumindo-se a dos preponentes. Nesse sentido são as normas dos arts. 159, 1521, III, e 1545 do Código Civil de 1916 e, atualmente, as dos arts. 186 e 951 do novo Código Civil, bem com a súmula 341 - STF (É presumida a culpa do patrão ou comitente pelo ato culposo do empregado ou preposto", de modo que não comporta guarida a assertiva de que a responsabilidade do hospital seria objetiva na hipótese." (Brasil. STJ. 2013 b).

6 "O conceito de malpractice, para o Ballentine's Law Dictionnary, faz uso da atuação médica: "o erro, pelo qual um médico ou cirurgião é responsável perante seu paciente quando resulta lesão ao paciente, consiste na falta daquele grau razoável de informação, habilidade e experiência que ordinariamente são possuídas por outrem em sua profissão, na omissão em proporcionar razoável cuidado e diligência na execução de sua técnica e na aplicação de seu conhecimento, ou na sua falha em exercer o melhor julgamento no caso que Ihe foi confiado. (Ballentine, 1969, p. 769).
} 
prognóstico. O erro pode não se limitar a ser técnico, podendo ser até mesmo uma "falha de humanismo", assim entendida como "mais uma falta moral do que profissional, já que ela não possui nada de falta técnica", inserindo-se nos deveres humanos dos médicos em relação aos pacientes (Bernard, 2010, p. 151). ${ }^{7}$ A falta técnica é igualmente grave, traduzindo na imperícia, imprudência ou negligência do autor do fato, causando prejuízo que possa ser caracterizado como certo (e não eventual), direto (causado pelo profissional) e pessoal (só a vítima, a princípio, pode demandar pelo dano causado) (Dorsner-Dolivet, 2006, p. 140).

O fato é que, muito embora tradicionalmente se perquira a responsabilidade do médico, a maioria das questões consolidadas aplicáveis a tais profissionais se estende aos demais agentes da saúde, acrescidas as peculiaridades de cada área (Silva, 2007 a, p. 226). O fundamental é que se enquadre o regime de responsabilidade de todos esses profissionais na linha da obrigação de meio, ou seja, de não comprometimento com o resultado, mas de empregar todos os meios disponíveis e ao alcance do profissional para o atingimento de um objetivo (Silva, 2007 b, p. 15), em que pese o entendimento contrário para certas áreas da medicina. ${ }^{8}$ No entanto, se o profissional, por referência expressa sua, assumir a produção de uma meta específica, sua obrigação, a partir de sua vontade declarada, passará a ser de resultado.

Assim, temos que a responsabilidade dos profissionais da área da saúde se verifica nos termos do art. $14, \S 4^{\circ}$, do Código de Defesa do Consumidor, com a apuração da responsabilidade subjetiva, ou seja, com a necessária análise da culpa dos agentes envolvidos. O papel desempenhado pela prova, a partir de tal constatação, mostra-se questão nodal para o deslinde do processo com a apuração do efetivamente ocorrido, lembrando ser o caso, a partir da aplicação do Código de Defesa do Consumidor, da chamada inversão do ônus da prova, prevista no art. 6ํ․ VIII, do diploma legal, concedida a partir da presença do requisito da hipossuficiência ou da verossimilhança, sendo excessiva ser requerida a apresentação concomitante de tais

\footnotetext{
${ }^{7} \mathrm{O}$ autor cita como exemplo um caso em que o médico não se deteve a solicitar a autorização de seu paciente para a realização de exame HIV, julgado na Court d'Appel francesa.

${ }^{8}$ No caso dos cirurgiões plásticos, alinhamo-nos ao entendimento de que as circunstâncias e idiossincrasias de cada organismo, a par da subjetividade do que se entenda por 'resultado estético', também deva ser de meio, valendo-se o profissional da melhor técnica disponível, sempre informando o paciente das possíveis consequências indesejadas do procedimento, inerentes a todo e qualquer ato cirúrgico (Forster, 1997, p. 83).
} 
elementos. ${ }^{9}$ Aponte-se que a prova a ser produzida pelo paciente é difícil, e que deverá o julgador sopesar as peculiaridades do caso para compreender o ocorrido (Memeteau, 1985, p. 464).

Digno de nota a questão do dever de informação. Se, de um lado, os profissionais da saúde não podem prometer um resultado específico (sucesso em tratamento oncológico, por exemplo), certos deveres, todos oriundos da boa-fé objetiva, obrigam esses indivíduos a fornecerem todos os elementos necessários aos seus pacientes para que estes possam, tanto quanto possível, participar do processo decisório de escolha do procedimento a ser realizado, ou ao menos o compreendam, excepcionadas situações de emergência.

Pode-se afirmar que existe uma tripla proteção ao direito do paciente ser informado, como a regra em conduta médica. Primordialmente, em qualquer relação contratual que se estabeleça (e mesmo em âmbito pré-contratual, há que se dizer), é imprescindível que as partes que ali se relacionam atentem para a existência dos chamados deveres anexos impostos pela boa-fé objetiva (Gomes, 2008, p. 43) deduzida a partir do artigo 422 do Código Civil atual.

Tais deveres revelam-se num complexo de cuidados que as partes (MartinsCosta, 1999, p. 438), nessas relações, devem guardar uma para com a outra, dentre eles incluído o direito à informação. Não se admite, em qualquer relação contratual, que uma das partes oculte da outra quaisquer dados relevantes e que sejam (ou possam vir a ser) de interesse do outro.

Esse direito à informação também encontra guarida na perspectiva da relação de consumo que se estabelece entre paciente (enquanto consumidor) e médico (enquanto prestador de serviços), ${ }^{10}$ com previsão no artigo $6^{\circ}$, III, da Lei 8.078/90

\footnotetext{
9 "A inversão do ônus da prova, prevista no art. 6o, VIII, do Código de Defesa do Consumidor, fica a critério do juiz, conforme apreciação dos aspectos de verossimilhança das alegações do consumidor ou de sua hipossuficiência (Brasil. STJ, 2013 c). No mesmo sentido: "Prestação de contas. Segunda fase. Contrato bancário. Abertura de crédito em conta-corrente. Agravo retido. Inversão do ônus da prova. Inexistência dos requisitos. Afastamento. Julgamento antecipado. Solução da controvérsia. Dependência de prova. Produção indeferida. Cerceamento de defesa. Nulidade da sentença. 1. Ainda que reconhecida a relação de consumo havida entre as partes, a inversão do ônus da prova depende da verossimilhança das alegações ou da hipossuficiência do consumidor, requisitos não demonstrados na demanda." (Brasil. TJPR, 2013, p. 276).

${ }_{10}$ RESPONSABILIDADE CIVIL. CIRURGIA BARIÁTRICA. AÇÃO DE INDENIZAÇÃO. MÉDICO. RESPONSABILIDADE SUBJETIVA. INADEQUAÇÃO DO PROCEDIMENTO NÃO COMPROVADA. A doutrina distingue duas hipóteses de responsabilização médica: A responsabilidade decorrente da prestação do serviço direta e pessoalmente pelo médico como profissional liberal, e a responsabilidade médica decorrente da prestação de serviços médicos de forma empresarial, aí incluídos os hospitais.
} 
(Código de Defesa do Consumidor).

E, finalmente, a previsão do próprio Código de Ética Médica, em seu artigo 34, pois é vedado ao médico "deixar de informar ao paciente o diagnóstico, o prognóstico, os riscos e os objetivos do tratamento, salvo quando a comunicação direta possa the provocar dano, devendo, nesse caso, fazer a comunicação a seu representante legal”. Assim, ainda que possa se deslocar o sujeito que receberá a informação, é certo que o médico, e todos os demais profissionais da saúde, possuem o dever de prestá-la. Essa total omissão poderá apontar a presença do erro humanístico, apontado retro.

\section{Responsabilidade dos profissionais da saúde enquanto agentes ${ }^{11}$ públicos}

Apontadas apenas algumas das situações nas quais os profissionais da saúde podem ter de responder pelos danos causados em âmbito privado, cabe ponderar se a análise do comportamento do agente público de saúde é o mesmo. Não resta dúvida de que as falhas aos quais ambos estão expostas são rigorosamente as mesmas. Não se retira nenhum dever profissional dos agentes públicos enquanto tais, nem mesmo aqueles oriundos da boa-fé objetiva, mencionados acima.

Bem aponta Elio Sgreccia que o médico no sistema público de saúde atua como um "agente duplo", por possuir dois contratos distintos: um com o serviço nacional que o emprega e o remunera, e aquele havido com o paciente. $O$ risco,

Hipótese de responsabilidade decorrente da prestação do serviço direta e pessoalmente pelo médico, uma vez que o autor moveu a ação contra os profissionais que the prestaram os serviços. É a chamada responsabilidade subjetiva, prevista no artigo $14, \S 4^{\circ}$, do CDC, fazendo-se necessária a comprovação do agir culposo do profissional. Hipótese em que a prova dos autos atestou a adequação do procedimento adotado pelo réu. A prova pericial afirmou que o procedimento cirúrgico escolhido pelos médicos foi a opção adequada para tratar a patologia apresentada pelo paciente. No tocante ao direito à informação, trata-se de um dos direitos básicos do consumidor (art. 6o, III, do CDC), e tem por finalidade dotar o paciente de elementos objetivos de realidade que lhe permitam dar, ou não, o consentimento. Os elementos dos autos mostram que o demandante tinha conhecimento do procedimento a ser realizado, bem como da gravidade de sua doença. No caso restou provado que houve o adequado preparo do paciente através da equipe multidisciplinar. $O$ autor não comprovou a falha do dever de informar dos médicos, ônus que lhe incumbia, a teor do art. 333 , I, do CPC. Os elementos dos autos levam a crer que o demandante tinha conhecimento do procedimento a ser realizado, bem como da gravidade de sua doença. Apelação desprovida. (Brasil. TJRS, 2012).

${ }_{11}$ A substituição do vocábulo 'funcionário' pelo vocábulo 'agente' atende sugestão de Miguel Seabra Fagundes no sentido de que 'no concernente à responsabilidade civil das pessoas jurídicas de direito público, pelos danos que seus 'agentes' causem a terceiros, temos que seria próprio substituir a expressão 'funcionários' (...) como propriedade, por 'quaisquer agentes públicos'. Com isso, incorporarse-ia ao texto, afastando-se controvérsias acaso ainda suscetíveis, a lição dos tribunais, de sorte a ficar assente que do gari e do praça de pré ao Presidente da República, todo e qualquer servidor estatal compromete, quando agindo nessa qualidade, a responsabilidade civil por dano a terceiro, da entidade a que serve (Gonçalves, 2003, p. 176). 
como bem aponta o autor, é de que a relação de "aliança, confiança e assistência, que se cria entre o médico e paciente, torne-se secundária e desresponsabilizada" (Sgreccia, 2012, p. 701). Some-se a isto o fato de quem financia o agente também limita suas despesas, possivelmente afetando sua liberdade prescritiva e até mesmo diagnóstica (Sgreccia, 2012, p. 702). Além de reconhecer a necessidade do estabelecimento de diretrizes nacionais e de reforçar a formação bioética dos profissionais, o autor não oferece soluções.

O fato é que o Sistema Único de Saúde não pode se apresentar com um sistema de irresponsabilidade na área da saúde. Suas notórias limitações e entraves burocráticos devem ser sopesadas quando da apuração da responsabilidade de algum dos agentes públicos envolvidos em situação de potencial erro profissional, mas isso jamais pode representar, a priori, a inexistência de responsabilidade individual.

Todo o dano passível de reparação, imputável a um ofensor, através da via do nexo causal, merece ser objeto de ressarcimento. O risco de entendimento contrário seria evidente questão de saúde pública: os agentes públicos da área da saúde atuariam em sistema que não os responsabiliza. À toda evidência, suas ações não seriam eivadas do mesmo cuidado do que aquelas ações entendidas como responsáveis.

Só que esses agentes não responderiam diretamente à vítima, porquanto não possuem legitimidade passiva para responderem tal demanda. Sendo a responsabilidade estatal, não se pode, no primeiro momento, demandar diretamente em face dos agentes estatais. ${ }^{12}$ Mas não podem se furtar, por completo, da responsabilidade que lhes cabe na ação regressiva. A diferença que se verifica, portanto, entre a qualidade de profissional da saúde no âmbito privado ou público não é a inexistência de responsabilidade sob o regime do SUS, e sim, por se tratar de serviço público, que o(s) entes político(s) estatal(is) diretamente responsável(is) Município, Estado ou União Federal - deverá(ão) responder perante o ofendido,

\footnotetext{
${ }^{12}$ Nesse sentido: "Nos termos da Constituição Federal, e consoante a teoria do risco administrativo adotada pelo ordenamento jurídico pátrio, no caso de danos advindos da conduta do agente público, somente o poder público deverá ser acionado, reservado seu direito de regresso em caso de dolo ou culpa do agente. Assim, os médicos são ilegítimos para o polo passivo da relação processual da ação indenizatória por danos morais e estéticos oriundos de possível erro médico. 4. Recurso não provido. Unânime." (Brasil. TJDF, 2013, p. 137).
} 
cabendo-Ihes ação regressiva em face do agente causador do dano, desde que presente seu dolo ou culpa.

\section{Responsabilidade nosocomial público e privada}

Em derradeiro, cabe realizar breve nota acerca da responsabilidade dos hospitais, diretamente envolvidos nos casos em que se apure responsabilidade por danos causados a paciente. Haveria diferença entre o hospital público e o hospital privado, para fins de responsabilidade? A resposta é afirmativa.

No âmbito da rede privada, se estabeleceu o entendimento jurisprudencial de que, embora seja objetiva a responsabilidade do nosocômio, o Código de Defesa do Consumidor, ao apontar a necessidade de verificação de culpa do médico na prestação do serviço defeituoso, criou um requisito para a responsabilização o hospital, que é a presença de culpa do médico. ${ }^{13}$ Não se olvida que a responsabilização do estabelecimento hospitalar poderá ser objetiva quando se trate de conduta não imputável à ação profissional do médico, ou seja, quando houver deficiências estruturais que concorram diretamente para o dano verificado ou no caso de infecção hospitalar, à exceção de quando tal condição se origine do estado já precário de saúde do paciente quando do início de seu tratamento (Bdine Júnior, 2007, p. 136; Laude et al., 2009, p. 455 e ss).

Já o estabelecimento público, por conta da teoria do risco administrativo, na

13 "APELAÇ̃̃O CÍVEL. RESPONSABILIDADE CIVIL. INFECÇÃO HOSPITALAR. AÇÃO DE INDENIZAÇÃO POR DANOS MORAIS. IMPROCEDÊNCIA MANTIDA. 1.Não conhecido o recurso na parte em que houve a alegação de falha do dever de informar e descumprimento do contrato de empenho, haja vista que não contidas na inicial da demanda, tratando-se de evidente inovação recursal, cujas causas alegadas não integram a presente lide, o que atenta aos princípios do contraditório e da ampla defesa. 2.Aplica-se a responsabilidade objetiva ao estabelecimento hospitalar pelos serviços prestados, na forma do art. 14, caput, do CDC, o que faz presumir a culpa do réu e prescindir da produção de provas a esse respeito, em razão de decorrer aquela do risco da atividade desempenhada. 3.O Hospital demandado apenas desonera-se do dever de indenizar caso comprove a ausência de nexo causal, ou seja, prove a culpa exclusiva da vítima, fato de terceiro, caso fortuito ou força maior. 4. Não obstante, para imputar a responsabilidade ao hospital, nos termos da legislação consumerista, tratando-se de demanda que discute a atuação técnica do médico que atendeu a demandante, cumpre verificar a ocorrência de culpa pelo profissional, ao qual se aplica a responsabilidade civil subjetiva, de acordo com o que preceitua o art. $14, \S 4^{\circ}$, CDC, de sorte a se aferir o nexo causal. Precedentes do STJ. 5.Na análise quanto à existência de falha no serviço prestado, bem como da culpabilidade do profissional, o Magistrado, que não tem conhecimentos técnico-científicos atinente à área médica, deve se valer principalmente das informações prestadas no laudo pericial. 6. No presente feito não assiste razão à autora ao imputar aos demandados a responsabilidade pelo evento danoso, na medida em que não restou comprovado nos autos qualquer conduta culposa pelos profissionais que prestaram atendimento àquela, bem como não foi comprovado o nexo de causalidade entre a infecção apresentada e a assepsia no nosocômio demandado. Recurso conhecido em parte e nesta negado provimento ao apelo." (Brasil. TJRS. 2013 b). 
esteira da dicção do art. 37, §6 , da Constituição Federal, possui responsabilidade objetiva, pois os agentes da saúde que nele desenvolvem suas atividades estão sempre diretamente conectados a tal ente público. $O$ indivíduo lesado possui o direito de acionar diretamente o hospital, e este, na presença de dolo ou culpa do agente, poderá propor a ação regressiva, não podendo se impor tal ônus a quem sofreu o dano. ${ }^{14}$ Não se conjugam, na mesma perspectiva, estabelecimentos públicos e privados, sob o viés da responsabilidade. Anote-se que, independente da presença de personalidade jurídica do hospital público, responderá também o entre político ao qual estava filiado na demanda que pleitear reparação por danos ali causados. Não parece adequado a equiparação de responsabilidades público/privado somente na perspectiva subjetiva, eis que desapareceria a responsabilidade objetiva do Estado (e a teoria do risco administrativo como um todo) se sempre se exigisse analisar a conduta do agente público.

\section{Conclusão}

O tema da responsabilidade na área da saúde é bastante delicado, pois envolve não só a perspectiva do erro técnico como também da falha humanística, potencial geradora de dever de reparar ainda que o procedimento executado tenha sido tecnicamente perfeito. Some-se a isto o envolvimento de uma multiplicidade de participantes (pacientes, familiares, enfermeiros, auxiliares de enfermagem, médicos

\footnotetext{
14 "APELAÇÃO CÍVEL. RESPONSABILIDADE CIVIL. ADMINISTRAÇÃO PÚBLICA. ART. 37, §6º, DA CF. RESPONSABILIDADE OBJETIVA. ILEGITIMIDADE PASSIVA DO AGENTE. RECONHECIDA DE OFÍCIO. ATENDIMENTO DE ENFERMEIRO EM HOSPITAL PÚBLICO. ATENTADO AO PUDOR CONTRA MENOR. ATO ILÍCITO COMPROVADO. DANO MORAL RECONHECIDO. CRITÉRIOS DE FIXAÇÃO DA INDENIZAÇÃO. MAJORAÇÃO. CUSTAS E HONORÁRIOS ADVOCATÍCIOS. MAJORAÇÃO DA VERBA HONORÁRIA. 1. llegitimidade passiva do agente responsável pelo atendimento para responder diretamente pelo ilícito cometido na qualidade de agente municipal. Precedente da câmara e do Supremo Tribunal Federal. 2. Responsabilidade do estado. A responsabilidade civil da administração pública é objetiva na hipótese, devendo ser aplicada a teoria do risco administrativo, conforme a exegese do $\S 6^{\circ}$ do art. 37 da Constituição Federal. Assim, despiciendo investigar sobre eventual culpa ou dolo do estado, cumprindo apenas o esclarecimento sobre a existência do ato ilícito, do dano e do nexo de causalidade entre estes. 3. Danos morais. Fixação do valor, critérios de fixação. Majoração da quantia arbitrada pela sentença, em atenção ao caso concreto e aos parâmetros da corte. 4. Os honorários advocatícios sucumbenciais vão mantidos, uma vez que estabelecidos em atenção aos vetores do art. 20 , parágrafo $3^{\circ}$, do $\mathrm{CPC}$, mormente a natureza da causa e o trabalho desenvolvido. Ação extinta, de ofício, em relação ao agente público. Recurso de apelação do réu Éder prejudicado. Desprovimento do recurso do município. Parcial provimento do apelo do autor." (Brasil. TJRS, 2013 c). Nesse mesmo sentido: "Configurado o dano, atrofia testicular esquerda, que abalou a dignidade do autor, e o nexo de causalidade, já que adquirido por infecção hospitalar após cirurgia em hospital público, há de se imputar ao ente público o dever de reparação/compensação, na forma do art. $37, \S 6^{\circ}$, da Constituição da República, presentes os pressupostos da responsabilidade civil objetiva." (Brasil. TRF 1ª R., 2013, p. 923).
} 
- dentre as mais variadas especialidades, frequentemente em atendimento conjunto odontólogos, fisioterapeutas, nutricionistas, psicólogos, hospitais, entes públicos, dentre outros, e eventuais terceiros), que a complexidade acha-se evidente.

O fato é que existem critérios objetivos aplicáveis à ampla maioria dos casos a fim de apurar eventuais responsabilidades (como o critério da obrigação na área da saúde ser tradicionalmente encarada como sendo de meio), que não podem ser desvirtuados quando há o envolvimento de qualquer tipo de ente político. A existência da questão social na saúde, ou seja, de que existe uma limitação para alocação de recursos, não pode remover do cenário obrigacional o elemento da responsabilidade dos danos efetivamente causados. Por outro lado, um erro pode não acontecer de maneira isolada, mas apresentar-se de maneira sistêmica, lesando um número maior de pessoas do que um indivíduo apenas, tornando a falha médica questão que pode ser encarada com facilidade como conectada à saúde pública. ${ }^{15}$

A partir deste breve exame da responsabilidade dos agentes públicos na atuação em questões de saúde, verifica-se que o Sistema Único de Saúde não pode apontar para uma irresponsabilidade de tais agentes, nem a isenção de todos os órgãos políticos. Por outro lado, a compreensão da jurisprudência pátria aponta no sentido de que o SUS não se presta a oferecer responsabilidade solidária irrestrita em todo e qualquer situação de erro médico, mas apenas nos casos que envolvam solicitações de medicamentos não regularmente fornecidos na rede pública.

\section{Referências}

BALLENTINE's Law Dictionary. $3^{a}$ ed. Nova lorque: Lawyers Cooperative Publishing, 1969.

BDINE JÚNIOR, Hamid Charaf. Responsabilidade Civil em infecção hospitalar e na anestesiologia. In SILVA, Regina Tavares da. (org.) Responsabilidade Civil na Área da Saúde. São Paulo: Saraiva, 2007.

BERNARD, Michel. 160 questions em responsabilité médicale. $2^{2}$ ed. Issy-lesMoulineaux : Masson, 2010.

BRASIL. Tribunal de Justiça do Estado do Rio Grande do Sul (TJRS). APL-RN 145383-82.2012.8.21.7000; Caxias do Sul; Sexta Câmara Cível; Rel. Des. Niwton Carpes da Silva; Julg. 29/08/2013. Diário da Justiça do Rio Grande do Sul (DJERS) 12/09/2013 (a).

\footnotetext{
15 "É um problema de saúde pública todo aquele que diz respeito ao bem estar de uma coletividade e reúne ações coletivas" (Fassin, 2004, p. 1017).
} 
BRASIL. Tribunal de Justiça do Estado do Rio Grande do Sul (TJRS). Apelação Cível № 0211241-26.2013.8.21.7000, Quinta Câmara Cível, Tribunal de Justiça do RS, Relator: Jorge Luiz Lopes do Canto, Julgado em 11/09/2013; Diário da Justiça do Rio Grande do Sul (DJERS) 13/09/2013 (b).

BRASIL. Tribunal de Justiça do Estado do Rio Grande do Sul (TJRS). AC 11782334.2013.8.21.7000; Canoas; Nona Câmara Cível; Rela Des ${ }^{a}$ Marilene Bonzanini Bernardi; Julg. 14/08/2013; Diário da Justiça do Rio Grande do Sul (DJERS) 20/08/2013 (c).

BRASIL. Tribunal de Justiça do Estado do Rio Grande do Sul (TJRS). AC 426779-34. 2011.8.21.7000; Porto Alegre; Décima Câmara Cível; Rel. Des. Túlio de Oliveira Martins; Julg. 15/12/2011; Diário da Justiça do Rio Grande do Sul (DJERS) 24/01/2012.

BRASIL. Tribunal de Justiça do Estado do Paraná (TJPR). ApCiv 0997414-7; Cascavel; Décima Quinta Câmara Cível; Rel. Des. Hamilton Mussi Correa; Diário da Justiça do Paraná (DJPR), 19/03/2013.

BRASIL. Tribunal de Justiça do Distrito Federal e Territórios (TJDFT). Rec 2013.00.2.013845-8; Ac. 699.605; Segunda Turma Cível; Rel ${ }^{a}$ Des $^{\underline{a}}$ Fátima Rafael; Diário de Justiça do Distrito Federal e territórios (DJDFT) 12/08/2013.

BRASIL. Tribunal Regional Federal da $1^{\underline{a}}$ Região (TRF 1a R). APL 000023389.2006.4.01.3502; Sexta Turma; Rel. Des. Fed. Jirair Aram Meguerian; Diário da Justiça Federal - 1ª Região (DJF1), 26/04/2013.

BRASIL. Superior Tribunal de Justiça (STJ). REsp 774.963/RJ, Rel. Ministra Maria Isabel Gallotti, Quarta Turma, julgado em 06/12/2012, Diário da Justiça (DJe), 07/03/2013. (a)

BRASIL. Supremo Tribunal de Justiça (STJ). AgRg nos EDcl no REsp 1218845/PR, Rel. Ministro Arnaldo Esteves Lima, Primeira Turma, julgado em 03/05/2012, Diário da Justiça (DJe), 20/09/2012.

BRASIL. STJ. AgRg no Ag 1261145/SP, Rel. Ministro Raul Araújo, Quarta Turma, julgado em 13/08/2013, Diário da Justiça (DJe), 03/09/2013. (b)

BRASIL. STJ. AgRg no AREsp 300.550/SP, Rel. Ministro Raul Araujo, Quarta Turma, julgado em 28/05/2013, Diário da Justiça (DJe), 24/06/2013. (c)

DORSNER-DOLIVET, Annick. La responsabilité du médecin. Paris: Economica, 2006.

FASSIN, Didier. Verbete Santé Publique. In: LECOURT, Dominique (org.). Dictionnaire de la pensée médicale. Paris: PUF, 2004.

FRANÇA, Genival Veloso de. Direito Médico. 9ª ed. Rio de Janeiro: Forense, 2007.

FORSTER, Nestor José. Erro Médico. São Leopoldo: UNISINOS, 2003.

. Cirurgia plástica estética: obrigação de resultado ou obrigação de meios? Revista dos Tribunais, São Paulo, 738:83, 1997.

GOMES, Orlando. Contratos. 26를 ed. Rio de Janeiro: Forense, 2008.

GONÇALVES, Carlos Roberto. Responsabilidade Civil. 8aa ed. São Paulo: Saraiva, 2003. 
KRESS, Hermut. Ética Médica. Traduzido do alemão por Hedda Malina. São Paulo: Edições Loyola, 2008.

LAUDE, Anne; MATHIEU, Bertrand e TABUTEAU, Didier. Droit de la Santé. $2^{\underline{a}}$ ed. Paris: PUF, 2009.

LECOURT, Dominique (org.). Dictionnaire de la pensée médicale. Paris: PUF, 2004. MARTINS-COSTA, Judith. A boa-fé objetiva no direito privado. São Paulo: RT, 1999. MEMETEAU, Gérard. Le droit médical. Paris: Litec, 1985.

SARLET, Ingo; MARINONI, Luiz Guilherme e MITIDIERO, Daniel. Curso de Direito Constitucional. São Paulo: RT, 2012.

SGRECCIA, Elio. Manuel de Bioéthique. Traduzido do italiano por Virginie Leclerq. T. 2. Paris: Mame-Desclée, 2012.

SILVA, Regina Tavares da. Responsabilidade Civil de outros profissionais na área da saúde. In: SILVA, Regina Tavares da. (org.) Responsabilidade Civil na Área da Saúde. São Paulo: Saraiva, 2007 (a).

SILVA, Regina Tavares da. Pressupostos da responsabilidade civil na área da saúde. In: SILVA, Regina Tavares da. (org.) Responsabilidade Civil na Área da Saúde. São Paulo: Saraiva, 2007 (b). 